\title{
Demand and Supply Status of Improved Seed and Factor Governing It in Ethiopia
}

\author{
Temesgen Teressa* \\ 1.Melkassa Agricultural Research Center, P.O Box 346 Adama, Ethiopia \\ 2.Ethiopian Institute of Agricultural Research P.O Box 2003 Addis Ababa, Ethiopia \\ 3.Crop research Directorate, Ethiopian Institute of Agricultural Research \\ 4.Jimma University Colleges of Agriculture and Veterinary Medicine P.O Box 307 Jimma, Ethiopia \\ Corresponding Author: Temesgen Teressa Ayana, Melkassa Agricultural Research Center, Ethiopian Institute of \\ Agricultural Research
}

\begin{abstract}
Seed is among the most key input for improving crop production and productivity. The use of improved, high yielding crop varieties is an important way for reducing hunger and food insecurity in developing countries. Increasing the quality of seeds can increase the yield potential of the crop by significant folds. Hence, access to and uses of seeds are critical factors for the ability of smallholder farmers to increase agricultural production and productivity, for improving livelihoods. The Ethiopia seed system has undergone tremendous changes. But, still the sector is unable to guarantee farmers' access to seed of improved varieties, in the right quantity, of the right quality, and in a timely manner, mainly because of the absence of linkage and integration among the stakeholders; there is a substantial gap exists between the production and supply of commercial seed and farmers' demand. On average, 12 million hectares of land is cultivated by major food crops over the last five years in Ethiopia, of which $10,979,645$ hectares was covered by non-improved local seeds. Which of the total annual arable land coverage by major food crops, $96.5 \%$ is covered by local seed and 3.5\% is by improved seeds. The annual average seed demand for cereals and pulses is estimated to be over 400,000 tons. Demand for improved seed is still increasing rapidly from time to time over the last years. So, improve basic facilities, infrastructure, improve productivity gaps, establish strong coordination between producer, processor and delivery is compulsory.
\end{abstract}

Keywords: Seed, demand, supply, improved

DOI: $10.7176 / \mathrm{JBAH} / 9-3-04$

\section{INTRODUCTION}

Ethiopia is predominantly an agrarian country with the vast majority of its population directly or indirectly being involved in the production of crop and livestock. Hence, agriculture plays a vital role in Ethiopian economy. According to (Astatkie et al., 2012) Agriculture in Ethiopia contributes about $45 \%$ of the GDP, $85 \%$ of the total exports and more than $85 \%$ of employment. But, still the sector is not yet adequately commercialized to bring about rapid change in production in line with increasing population pressure (Alemu, 2012). The problem is not that Ethiopia is poorly endowed with agricultural resource; instead the problem is that new technologies have not been permitted to make any inroads into Ethiopian agriculture.

As (Atilaw, 2010) states that Agriculture in Ethiopia is caught in a low input-low output trap, due in part to low levels of investment, low technology application, and low capacity. The solution needs to involve a structural change, for which major capacity development is needed, including a quantum change in human capacity, input supply, technology adoption, and provision of infrastructure. Specially, in order to increase the production and productivity of agricultural output, the use of modern agricultural technologies are vital, out of which fertilizer and high yielding variety of crops are the most important technologies to increase the level of crop production.

Seed is one of the most key input for improving crop production and productivity (Beyene, 2010; Mugonozza, 2001). Increasing the quality of seeds can increase the yield potential of the crop by significant folds and thus, is one of the most economical and efficient inputs to agricultural development (FAO, 2006).

Despite the release of several technologies, particularly of improved crop varieties, there has been limited use of improved seeds by the majority of farmers (CSA, 2010) and the presence of several seed companies, the agricultural input sector in Ethiopia is currently not able to satisfy the demand for improved seed in the country (MOA, 2013). Deficiencies have been also observed in improved seed supply due to the seed varieties demanded and quantities required, and untimely seed delivery (Bishaw and Turner, 2008; Sahlu et al., 2008).

Generation and transfer of improved technologies are critical prerequisites for agricultural development particularly for an agrarian based economy such as of Ethiopian. Among others, unavailability of quality seeds at the right place and time coupled with poor promotion system, is one of the key factors accounting for limited use of improved seeds, which further contributing for low agricultural productivity. Poor availability and promotion of improved seeds is due to inefficiency of the seed systems of the country.

Sustainable seed system will ensure that high quality seeds of a wide range of varieties and crops are produced and fully available in time and affordable to farmers and other stakeholders. However, in Ethiopia like in many 
developing countries farmers have not yet been able to fully benefit from the advantages of using improved seed. So, the objectives of this paper are: To review the demand and supply Status of improved seeds in Ethiopia and to identify the factors that influences the improved seeds.

\section{LITERATURE REVIEW}

\subsection{Seed production in Ethiopia}

In Ethiopia the role of cooperatives in seed multiplication is increasing from time to time. They are already engaged in seed production, cleaning and trading of Quality Declared Seeds (QDS) of OPV. However, the supply of seeds of adapted improved crop varieties is in shortage for such program (Alemu, 2010).

It is expected that the emergence of regional seed enterprises will promote the production of seed for crops that are not so far produced through the formal system. For instance, the Amhara and Oromiya Seed Enterprises (ASE) has promoted Farmers' Based Seed Multiplication Scheme (FBSMS) immediately after its establishment in early 2009 with a focus on potential areas for seed multiplication and clustering approach. The major challenges in the FBSMS are the limited capacity of the seed enterprise both ESE and regional SE to purchase timely from farmers, limited capacity of facilities like harvesting and threshing, cleaning and grading facilities, and storage(Alemu, 2010).

In Ethiopia Only 2.9\% of the farmers reported to use improved seed in 2011 (CSA and MOFED, 2011: 20). The contribution of the formal seed sector as a percentage of cultivated land was only 5.4\% in 2011, with considerable variability among different crops (Spielman et al., 2011). Low technology adoption rates can have many reasons (Degu et al., 2000; Feder and Umali, 1993). One important reason is the substantial lack of improved seed (MOA, 2013).

Seed multiplication by ESE focused mainly on two cereal crops (wheat and maize) and annual supply of improved seed by the enterprise doesn't exceed 20,000 tons (Marja et al., 2008, Atilaw 2010). Wheat and maize constitute about $85 \%$ of the total output of the enterprise.

Table 1 Area cultivated by major crops from 2013/14 to 2016/17 cropping season

\begin{tabular}{|l|l|l|l|l|l|}
\hline \multirow{2}{*}{ Crops } & \multicolumn{5}{|c|}{ Cropping seasons } \\
\cline { 2 - 6 } & $2013 / 14$ & $2014 / 15$ & $20015 / 16$ & $2016 / 17$ & $2017 / 18$ \\
\hline Cereals & $8,072,561$ & $8,463,080$ & $8,730,001$ & $8,770,118$ & $9,233,025$ \\
\hline Pulses & $1,292,063$ & $1,517,662$ & $1,517,662$ & $1,585,236$ & $1,489,308$ \\
\hline Oil crops & 796,397 & 740,847 & 707,059 & 855,147 & 780,916 \\
\hline Vegetable & 117,578 & 162,125 & 119,091 & 95,194 & 138,393 \\
\hline Root crops & 168,836 & 188,917 & 184,329 & 145,742 & 212,208 \\
\hline Other annuals & 77,554 & 97,677 & 84,977 & 69,103 & 63,418 \\
\hline Permanents & 767,582 & 823,121 & $1,039,313$ & 906,518 & 53,086 \\
\hline Total & $11,292,571$ & $11,787,775$ & $12,382,432$ & $12,493,989$ & $11,970,354$ \\
\hline
\end{tabular}

Source: CSA, 2013-2017

It is reported that over the last five years (2013-2018), on average more than 12 million hectare of land are cultivated by the major food crops (Table 1). These are: cereals, legumes, oilseeds, root crops and horticultural crops.

Table 2 Area covered by improved seeds during 2013/14 to 2017/18 cropping season

\begin{tabular}{|c|c|c|c|c|c|}
\hline \multirow[b]{2}{*}{ Crops } & \multicolumn{5}{|c|}{ Cropping season } \\
\hline & $20013 / 14$ & $2014 / 15$ & $2015 / 16$ & $2016 / 17$ & $2017 / 18$ \\
\hline Cereals & 429,536 & 335,369 & 412,629 & 430,937 & 322,819 \\
\hline Pulses & 5,224 & 5,025 & 6,309 & 14,918 & 12,912 \\
\hline Oil crops & 1,833 & 4,056 & 2,273 & 2,328 & 9,139 \\
\hline Vegetable & 779 & 559 & 501 & 1,899 & 2,788 \\
\hline Root crops & 813 & 2,114 & 2,251 & 799 & 3,721 \\
\hline Other annuals & 70 & 102 & - & - & - \\
\hline Permanents & 9,681 & 11,742 & 5,828 & 13,120 & 9,852 \\
\hline Total & 447,936 & 358,967 & 429,791 & 464,001 & 361,231 \\
\hline
\end{tabular}

Source: CSA, 2013-2017

\subsection{Economic importance of improved seeds}

\subsubsection{Higher yields}

According to (CSA,2016) improved seed gives a significantly higher yield, and better quality of crop products compared to locally produced variety of seeds. Higher yields are achieved when seed heads produce more seeds per head or bigger seeds; but plants with tall stalks cannot always support the added weight. In the 1960s, as India was facing famine, the American agronomist Norman Borlaug developed dwarf wheat varieties with stalks that 
could support larger seeds and brought them to Punjab. By 1970, wheat yields in Punjab had tripled, provided the seeds were given sufficient water and synthetic fertilizer (Nelson et al. 2007; Van Breusegem et al,.1999 a, b)

2.2.2 Improved nutrition

To make diets more nutritious, the first is to promote varieties of seed that have been bred to be more nutritious. Since 70 to 80 percent of the developing world's diet consists of carbohydrates, the idea is to pack more nutrients into the staple crops. For example international agricultural research, works on boosting micronutrients in seven staple crops the people of Asia and Africa most eat cassava, maize, rice, wheat, sweet potato, beans and pearl millet. Iron, zinc and vitamin A are the micronutrients usually lacking in the diets of millions of people.

2.2.3 High germination rate and vigor

Germination is reported as the percentage of seed producing normal seedlings. Normal seedlings are those that produce a vigorous set of primary and secondary roots; have a healthy hypocotyls, epicotyls, and cotyledon; and produce a healthy shoot meristem. Abnormal seedlings would not be counted in the total percent germination for that sample. Seed vigor is the property that gives seed the potential for rapid and uniform emergence and development of normal seedlings under a wide range of field conditions.

2.2.4 High quality

Seed quality describes the potential performance of a seed lot. Trueness to variety; the presence of inert matter, seed of other crops, or weed seed; germination percentage; vigor; appearance; and freedom from disease are important aspects of seed quality. High-quality seed lots should meet minimum standards for each of these characteristics. The standards of official certification agencies are usually accepted as the minimum requirements for high quality seed.

\subsection{Concept of Seed systems in Ethiopia}

The Ethiopian seed system has been evolving in attempt to ensure the availability required type of seed in the required quantity and quality at affordable price and time. Seed system in Ethiopia represents the entire complex organizational, institutional, and individual operations associated with the development, multiplication, processing, storage, distribution, and marketing of seed in the country (Abebe and Lijalem, 2011).

Seed systems in Ethiopia can be divided into two broad types: the formal system and the informal system (sometimes called local or farmers seed system). Both systems are operating simultaneously in the country and difficult to demarcate between the two. There is however, a fact that the formal system is the original source of improved seeds in the informal system (Maredia, et al., 1999).

According to Bishaw et al. (2008), the Ethiopian formal seed system was introduced five decades ago with the activities of crop improvement research by the existing research and higher learning institutes; nevertheless, it has not developed as expected due to multiple reasons (Yonas, 2012) related to lack of organizational set up, inadequacy of on trained manpower and limited private participation.

The major actors of the formal systems in Ethiopia are, NARS, MoA, ESE and private seed companies specializing on specific crops like Pioneer. Recently, regional seed enterprises (RSE) were also established as public seed enterprises. All actors have inter-dependent roles in the system and inefficiency of one actor will automatically affect negatively the performances of the rest of the actors (Maredia, et al., 1999).

In the context of Ethiopia, the informal system is extremely important for seed security. The bulk of seed supply is provided through the informal system, implying its importance in national seed security. The informal seed system (either self-saved seed or farmer-to-farmer seed exchange) accounts for $90 \%$ of the seed used by smallholder farmers (Belay, 2004), while the share of improved seed is less than 10\% (FAO-CDMDP, 2010).

As stated in Abebe and Lijalem (2011) the key reasons why the majority of Ethiopian farmers show a tendency of depending on the informal system are; it is relatively cheaper and readily available in the farmer's villages at required time and it allows use of seeds after testing on primary adopter farmers.

Table 3 Area coverage of informal and formal seed system during 2005/06-2009/10

\begin{tabular}{|l|l|l|l|l|l|}
\hline Seed system & $2013 / 14$ & $2014 / 15$ & $2015 / 16$ & $2016 / 17$ & $2017 / 18$ \\
\hline Informal & $10,821,810$ & $11,427,794$ & $11,927,093$ & $12,010,042$ & $10,136,744$ \\
\hline Formal & 447,936 & 358,967 & 429,791 & 464,001 & 361,231 \\
\hline \% informal & 96.03 & 96.95 & 96.52 & 96.28 & 96.56 \\
\hline \% formal & 3.97 & 3.05 & 3.48 & 3.72 & 3.44 \\
\hline
\end{tabular}

Source: CSA, 2013-2017

\subsection{Seed demand and supply in Ethiopia}

Seed security is one of the most important sociological, political, economic and scientific challenges in the country. Securing the supply of quality seed and planting materials of the most important food crops is the most effective way to sustain food security (Marja H. et al., 2008).

Seed demand is increasing from time to time in Ethiopia. The public seed production is dominated by Ethiopian Seed Enterprise (ESE) and since 2008 regional seed enterprises (RSEs) have come into the picture, at 
present there are two RSEs, Oromiya Seed Enterprise (OSE) and Amhara Seed Enterprise (ASE) (Alemu, 2010). The establishment of Ethiopian Seed Enterprise's led to advent of organized seed production and supply system in the country and remained the main supplier in the formal sector (Abebe and Lijalem, 2009).

In the country, the supply of improved seeds never fulfilled the need of producers. But for the last two years with the shift in seed multiplication strategy, the production of improved seeds especially hybrids maize and wheat were considerably improved.

In $2011 / 12$, seed supply covered only $51 \%$ of stated demand for barley, $24 \%$ for wheat, $16 \%$ for rice, $30 \%$ for millet and $60 \%$ for fababean. The supply of maize, wheat and teff seeds has improved considerably over the last years. But still, only $20 \%$ of the area cultivated with maize, $4 \%$ of the wheat area and less than $1 \%$ of the teff area are cultivated with seed from the formal sector (CSA, 2012).

Table 4 Difference between supply and demand of improved seed of various crops

\begin{tabular}{|l|l|l|}
\hline Crops & Difference between demand and supply in quintals (2011/12) & \% of demand not met \\
\hline Wheat & 200,720 & 21 \\
\hline Teff & 10,211 & 11 \\
\hline Maize & 39,666 & 9 \\
\hline Barley & 101,924 & 49 \\
\hline Sorghum & 16,433 & 92 \\
\hline Rice & 13,638 & 84 \\
\hline Millet & 967 & 70 \\
\hline Fababean & 19,918 & 40 \\
\hline Field pea & 47,769 & 84 \\
\hline Chick pea & 11,035 & 63 \\
\hline
\end{tabular}

Source: MoA (2013)

Table 5 Demand and supply of hybrid and non-hybrid seeds from 2015-2016

\begin{tabular}{|l|l|l|l|l|l|l|}
\hline Production year & \multicolumn{3}{|c|}{ Hybrid seed } & \multicolumn{3}{c|}{ Non-hybrid seed } \\
\hline & Demand & Supply & \%Supply & Demand & Supply & \%Supply \\
\hline $2007 / 08$ & 123,777 & 35,244 & 28.47 & 62,9422 & 205,680 & 32.68 \\
\hline $2008 / 09$ & 143,847 & 86,787 & 60.33 & 841,458 & 246,051 & 29.24 \\
\hline $2009 / 10$ & 193,079 & 95,735 & 49.58 & 737,992 & 278,353 & 37.71 \\
\hline $2010 / 11$ & 333,249 & 193,123 & 57.65 & 723,588 & 433,049 & 59.85 \\
\hline
\end{tabular}

Source: MoARD, 2016

\subsection{Seed distribution and marketing system}

Seed dissemination involves the mechanisms through which seed and information about it are moving from one to the other actor. Informal social networks serve as a means to share information. Understanding the preference of seed producers is useful to establish a sustainable seed supply system and influence the perception of seed producers and users favorably (Beyene, 2010).

Seed marketing is a vital link between the seed producers and the farmers that ultimately use the seeds. Although significant public resources are invested in the public plant breeding and multiplication, the products are not reaching farmers. Open pollinated variety seed that is available is often stockpiled in farmer unions and cooperatives, and ineffective distribution mechanisms hinder the reach of existing seed (Alemu, 2010).

Distribution of seed currently happens only through existing institutions, such as cooperatives and farmer unions, and is a constraint to the meaningful development of the private seed sector. Based on the demand planning process, MoARD instructs ESE on the type and quantity of seed to be delivered to cooperative unions, who in turn provide the seed to the primary cooperatives and farmers under them. This centralized system leaves cooperatives and farmers with relatively little flexibility in determining the type of seed they get, when they get seeds or choice of suppliers (Alemu, 2010)

\subsection{Factors that governs improved seeds in Ethiopia}

Low crop productivity in sub-Saharan Africa (SSA), including Ethiopia, is due to limited use of seeds of improved varieties by smallholder farmers. The supply of improved seeds of grain crops in Ethiopia is estimated to be about $10 \%$ of the annual seed planted (Spielman et al., 2010).

Seed is a divisible and scale-neutral technology that can be adopted by different types of farmers from resource poor to rich (Feder et al., 1985). However, deficiencies of improved seed supply due to high prices, the seed varieties demanded and quantities required, and untimely seed delivery (Bishaw and Turner, 2008; Sahlu et al., 2008).

As outlined in recent FAO reports, over $90 \%$ of the fields in Ethiopia are still planted with farmers' varieties and farm saved seeds. In the informal seed system, individual farm households carry out all seed functions, 
including variety selection, multiplication, processing and marketing.

The extent of farmers seed use is influenced by several factors such as availability, finance, pricing, timing and awareness and factors like shortage combined with institutional factors related to transportation and distribution of seeds.

According to (Dawit Alemu, 2011), about 80\% (including both regular and irregular users) used seed of improved wheat varieties though the proportion of regular users was limited only to $33.7 \%$ in the past five years.

Irregularities in seed use are attributed to shortage of supply (29\%), lack of finance $(24 \%)$, high seed price $(22 \%)$, untimely supply (12\%), lack of awareness on seed of improved varieties $(12 \%)$, and lack of trust on quality of improved seed or suppliers $(12 \%)$.

Table 6 Reasons that hindered utilization of seeds of improved varieties

\begin{tabular}{|l|l|l|l|l|}
\hline Reason raised by irregular users & $\begin{array}{l}\text { Oromiya } \\
\mathrm{N}=311\end{array}$ & $\begin{array}{l}\text { Amhara } \\
\mathrm{N}=210\end{array}$ & $\begin{array}{l}\mathrm{SNNP} \\
\mathrm{N}=235\end{array}$ & $\begin{array}{l}\text { Total } \\
\mathrm{N}=756\end{array}$ \\
\hline Shortage of supply & 28.0 & 33.3 & 27.6 & 29.4 \\
\hline Lack of finance & 24.4 & 26.2 & 21.7 & 24.1 \\
\hline High price & 22.0 & 22.0 & 22.5 & 22.1 \\
\hline Untimely supply & 16.7 & 18.6 & 20.0 & 12.3 \\
\hline Lack of awareness/Interest & 9.0 & 12.4 & 16.6 & 12.3 \\
\hline Lack of trust on (improved seeds and suppliers) & 10.0 & 13.0 & 14.5 & 12.2 \\
\hline
\end{tabular}

Journal of Biology and Agriculture, 2015

$* \mathrm{~N}=$ Number of farmers sampled for interviewed

2.6.1 Poorly developed infrastructure

Long distances between farmers' fields and seed outlets, poorly maintained roads, high transportation costs and inadequate storage arrangements have a negative impact on seed production, quality and affordability (Abraha, 2013).

2.6.2 Inadequate extension services

In many countries, including Ethiopia, extension services are not readily available or easily accessible (Spielman et al., 2011). Farmers often need such services to guide their decision making on production and use of quality seeds and to understand the benefits.

2.6.3 Policy and regulatory constraints

The national seed policy and relevant laws and regulations have not been revisited and amended to keep up with new developments in the industry. A number of articles need to be amended, particularly with regard to seed quality standards, which are very high for some crops.

The Seed Law No. 206/2000 demands conformity with these standards for any commercial seed. It proved impossible to achieve such standards at the current stage of development in the seed sector. This concern was noted by the responsible agency but no practical action is taken yet (Bishaw et al., 2008).

2.6.4 Inconsistent demand planning and target setting

The government's methods for estimating seed demand from farmers and subsequent seed production targets are inconsistent and inaccurate, leading to both over and under-estimation of demand. The allocation process is also slow, contributing to delivery delays; thus, there is a need for more reliable information about farmer seed demand to calibrate projections, including a better database of local and regional needs (Abraha, 2013).

Furthermore, planning is currently favorable to high potential areas, yet the low-potential areas are also a source of demand for improved seed. There is a case for GOE to play a stronger role in these areas (Abay F, 2011). 2.6.5 Lack of coordination between production, processing and delivery

The current processing, cleaning, testing and storage facilities are not aligned to major seed producing areas. Key resources remain concentrated in specific areas, increasing logistics costs and slowing delivery to remote areas (Food science and quality management, 2015).

2.6.6 Low participation of private sector in seed industry

For a sustainable national seed industry development, it is necessary that private seed sector participation flourishes. However the private seed sector is still undeveloped in the country. Special attention and support should be offered by the government particularly in making the working environment more encouraging to the private sector.

\section{SUMMARY AND CONCLUSION}

In Ethiopia almost the entire seed supply is based on rain fed seed production system. These are the key factors contributing for shortage of improved seed supply in the country. The major factor in the formal system, ESE is focusing mainly on two cereal crops, wheat, and maize; seeds of other crops are entirely supplied by the informal system (farmer-to-farmer seed exchange).

The majority of Ethiopian smallholder farmers are largely dependent on informal system, since system it providing cheaper and readily available in the farmers ${ }^{\text {ee }}$ village at the right time of seed is needed as a result of this farmers show a tendency of on the system. 
The role of improved seed, in alleviating poverty has been outlined the social and economic impact of improved varieties in where they have been widely grown. Because improved seed embodies a plant's genetic potential, it determines the upper limits on yield and even the productivity of other inputs.

Despite the importance of improved seed for bettering the welfare of small-scale farmers, access to this invaluable technology can be constrained by many factors, including an underdeveloped seed industry. A seed industry essentially consists of all enterprises that produce or distribute seed.

The review show that despite extensive varietal development by the public research systems, dissemination of improved varieties to farmers remains limited. Thus result in a limited seed market competition, insufficient supply of seed relative to demand, limited choice in the few varieties and excessively high costs of improved seed production.

There is a key role to be played by the private sector to bridge the gap between the supply and demand of seed, and make quality seed available to farmers in their villages in the right amount, at the right time and place. It is expected that the increased supply will also reduce prices, making the technology available to the poorer farmers.

Formal seed system is not yet developed. On the other hand, the informal (farmers') seed system is operating with limited resources from the farmers without significant support. Special attention and support should be offered particularly in making the working environment more encouraging, effective seed demand assessment, open involvement of farmers/users during planning, every seeds produced must be channeled into the seed system.

Development of irrigation capacity should be given the priority. Providing opportunities for capacity building, basic facilities, infrastructure, improve productivity gaps, establish strong coordination between producer, processor and delivery and launching clear and simple institutional and functional linkages between research and seed producing institutions; Capacitate experts and extension agents that can strengthen the adoption of improved seed.

So, that improved seed and quality couldn't be compromised; without significant structural and organizational change to the seed system, these market and institutional failures will continue to hinder small holder access to improved varieties developed for the farmers.

\section{REFERENCES}

Abay, F., de Boef, W. and Bjornstad, A., 2011. Network analysis of barley seed flows in Tigray, Ethiopia: supporting the design of strategies that contribute to on-farm management of plant genetic resources. Plant Genetic Resources, 9(04), pp.495-505.

Alemu, D., 2011. Farmer-Based Seed Multiplication in the Ethiopian Seed System: Approaches, Priorities \& Performance.

Alemu, D., 2012. The Political Economy of Ethiopian Cereal Seed Systems.

Alemu, D. and Spielman, D.J., 2006. The Ethiopian seed system: Regulations, institutions and stakeholders. International Food Policy Research Institute, Addis Ababa.

Alemu, D., Rashid, S. and Tripp, R., 2010. Seed system potential in Ethiopia: Constraints and opportunities for enhancing the seed sector. International Food Policy Research Institute. Washington DC. 62pp.

Amhara Regional State (2008): Document for establishment of Amhara Seed Enterprise. Government of Ethiopia, Addis Ababa.

Astatike, M., Yimam, A., Tsegaye, D., Kefale, M., Mewa, D., Desalegn, T. and Hassena, M., 2012. Experience of direct seed marketing in Amhara region (unpublished report). Local Seed Business, Addis Ababa.

Astatkie, M., Legesse, B. and Zerfu, E., 2012. Analysis of economic impacts of triticale (X-Triticosecale Wittmack) adoption: The case of Farta wereda.

Atilaw, A. and Korbu, L., 2011. Recent development in seed systems of Ethiopia. Improving Farmers' Access to Seed. Empowering Farmers' Innovation. Series, (1), pp.13-30.

Atilaw, A. and Korbu, L., 2012. Roles of public and private seed enterprises. T/Wold, A., Fikre, A., Alemu, D., Desalgn, L., Kirub, A.(Eds.), The Defining Moments in Ethiopian Seed System. Ethiopian Institute of Agricultural Research, Addis Ababa, pp.181-196.

Atilaw, A., 2010. A baseline survey on the Ethiopian seed sector. Submitted to the African Trade Association.

Belay, K. and Manig, W., 2004. Access to rural land in Eastern Ethiopia: Mismatch between policy and reality. Journal of Agriculture and Rural Development in the Tropics and Subtropics (JARTS), 105(2), pp.123-138.

Beyene, H., H. Verkuijl, and W. Mwangi. 2010. Farmers' Seed Sources and Management of Bread Wheat in the Wolmera Wereda, Ethiopia. Mexico, D.F/Addis Ababa: CIMMYT/IAR.

Bishaw, Z., Sahlu, Y. and Simane, B., 2008. The status of the Ethiopian seed industry. Thijssen, MH, Z. Bishaw, A. Beshir and WS de Boef, pp.23-32.

CSA (Central Statistical Agency) (2012): Agriculture - 2011. Vol.1. Central Statistical Agency, Addis Ababa.

CSA and MOFED (Ministry of Finance and Economic Development) (2011): Agricultural Sample Survey 201011. Study Documentation. Central Statistical Agency and Ministry of Finance and Economic Development, 
Addis Ababa.

CSA and MOFED (Ministry of Finance and Economic Development) (2011): Agricultural Finance and Economic Development, Addis Ababa.

Degu, G., Mwangi, W.M., Verkuijl, H. and Wondimu, A., 2000. An assessment of the adoption of seed and fertilizer packages and the role of credit in smallholder maize production in Sidama and North Omo Zones, Ethiopia. CIMMYT.

EIAR/FRG (2012). Ensuring seed quality in Ethiopian seed system, Status and challenges. FRG II project: empowering Farmers' innovation, Serious No.3.

Ethiopian Institute of Agricultural Research 2010. Annual report of the year. Addis Ababa, Ethiopia.

Ethiopian Seed Enterprise 2006-2010. Annual and Progress Reports. Addis Ababa, Ethiopia.

FAO-Crop Diversification and Marketing Development Project (2010). Seed Value Chain Analysis as a means for Sustainable Seed System: a case of farmers based seed production and marketing in Arsi Zone, Oromia Region. Assela, Ethiopia.

Feder, G. and Umali, D.L., 1993. The adoption of agricultural innovations: a review. Technological forecasting and social change, 43(3), pp.215-239.

Feder, G., Just, R.E. and Zilberman, D., 1985. Adoption of agricultural innovations in developing countries: A survey. Economic development and cultural change, 33(2), pp.255-298.

Louwaars, N., 2010. The formal seed sector in Ethiopia. A study to strengthen its performance and impact. Local Seed Bus Newsl, 3, pp.12-13.

Marja HT, B Zewdie, B Abdurrahman and S Walter. 2008. Farmers, Seeds and Varieties. Wageningen International, the Netherlands.

Maredia, M.K., Byerlee, D. and Pee, P., 1999. Impacts of food crop improvement research: evidence from subSaharan Africa. Food policy, 25(5), pp.531-559.

MoARD, 2009. Official documents and records from the Agricultural Extension Directorate. Addis Ababa: MoARD

MOA 2013: Data on demand and supply of improved seed of different crops. Ministry of Agriculture, Addis Ababa.

Mugonozza, S., 2001. Seed system in Africa. International Center for Agriculture Research in the Dry Areas, ICARDA. Nea Zealand Grassland Association, Palmerston North, pp.103-109.

Nelson, G.C. et al. (2007). Climate Change. Impact on Agriculture and Costs of Adaptation.IFPRI, Washington D.C

Spielman, D.J., Kelemwork, D. and Alemu, D., 2011. Seed, fertilizer, and agricultural extension in Ethiopia.

Spielman, D.J., Byerlee, D., Alemu, D. and Kelemework, D., 2010. Policies to promote cereal intensification in Ethiopia: The search for appropriate public and private roles. Food Policy, 35(3), pp.185-194.

Yonas Sahlu (2012). The Ethiopian seed quality control system. Ensuring seed quality in Ethiopian seed system,Status and challenges. FGR II project: empowering Farmers' innovation, Serious No.3. pp 9-15.

Zewdie, B., Sahlu, Y. and Simane, B., 2008. The status of the Ethiopian seed industry. Farmers, seeds and variefies: Supporfing informal seed supply in Ethiopia. Wageningen, Wageningen International, p.348. 